\title{
De pleitos, comisiones y eruditos: la historia de la «Cueva del Cubo» de Rueda del Almirante (León)
}

\author{
Vanessa JIMENO \\ Universidad de León
}

RESUMEN: A lo largo del margen derecho del valle medio del Esla se extiende una serie de conjuntos excavados de excepcional importancia para entender la arquitectura sustractiva altomedieval en territorio leonés, y aun en el hispano. A pesar de que a principios del siglo pasado gozaron de la atención de algunos miembros de las Comisiones de Monumentos Históricos y Artísticos, así como de la curiosidad de algunos eruditos locales, hoy, ya languidecientes, apenas han suscitado interés dentro de la comunidad científica.

El presente estudio pretende centrarse en el espacio excavado en la localidad leonesa de Rueda del Almirante por tratarse del más desconocido y arruinado de todos ellos, además de constituir un auténtico paradigma de la arquitectura excavada.

Palabras clave: Arquitectura excavada; Alta Edad Media; Cueva del Cubo; Rueda del Almirante; Comisión Provincial de Monumentos.

ABSTRACT: Along the right side of the Esla middle valley there are a big number of carved architecture which have a huge importance to know this architectural typology in the territory of León, even in the Hispanic one. In spite of the attention that the Monument Commissions and some local erudites payed to these caves, nowadays they haven't aroused interest within the scientific community.

The aim of the present article is to analyse the carved space in Rueda del Almirante (León) because is the most unknown and destroyed of all of them, as well as to constitute a real paradigm of the carved architecture.

Key words: Carved Architecture; High Middle Age; Cueva del Cubo; Rueda del Almirante; Monuments Provincial Commission.

\section{LAS PRIMERAS NOTICIAS DOCUMEN- TALES DE «LA CASERETA»: EL DIBUJO DEL MUSEO DE LEÓN}

Entre los numerosos y variados bienes que atesora el Museo Provincial de León se encuentra un singular mapa geográfico, inventariado con el número
1995/9/1, en el que aparece representada con sumo detalle la localidad leonesa de Rueda del Almirante y su entorno inmediato ${ }^{1}$ (Figura 1). Destacan, entre otros, algu-

\section{-}

${ }^{1}$ Agradecemos enormemente a D. Luis Grau Lobo, director del Museo de León, las facilidades que nos ha proporcionado en todo momento para poder llevar 
nos accidentes topográficos que configuran dicho lugar y han dado origen a ciertos topónimos como «La Atalaya», de la que Aurelio Calvo señalaba que "domina grande extensión de terreno en todas direcciones. Se nota que estaba en comunicación con el Castillo, pues existen vestigios del camino que enlazaba estos dos puntos"2; o la «calle del Rollo», aquella que conducía a la plaza del mismo nombre donde los reos eran ajusticiados, y de la que el mismo autor indicaba que "en la parte alta de la cuesta, donde está emplazado el pueblo, existía una plazuela, hoy casi desaparecida, que aún conocen con el nombre de El Rollo. Con motivo de un incendio ocurrido pocos años ha en una edificación próxima a las ruinas del Castillo, varios vecinos practicaron algunas excavaciones encontrando cascos de vasijas antiguas y otros análogos objetos; $\mathrm{y}$ al profundizar más, cuentan que llegaron a descubrir un hueco grande cuya terminación no hallaron, y al arrojar piedras en él, dicen que iban a perderse a lo lejos dejando tras sí un extraño y sonoro ruido" ${ }^{\prime 3}$.

Junto a esta relación de elementos paisajísticos el mapa también recoge la presencia una cavidad altomedieval excavada en la «Peña del Cubo» bajo la denominación, en este caso, de «La Casereta». Hasta el hallazgo de este documento cartográfico se desconcía tal término aplicado a la misma, pues popularmente ha sido conocida, al menos desde principios del siglo $\mathrm{XX}$, como la "Cueva del Cubo», designación que también se ha dado a la peña en la que se excavó, debido a su proximidad con

a cabo el presente análisis. De la misma manera, queremos hacer extensible este agradecimiento a los Doctores del Departamento de Patrimonio Artístico y Documental de la Universidad de León, D. Santiago Domínguez Sánchez y D. Joaquín García Nistal.

2 A. Calvo, El monasterio de Gradefes. Apuntes para su historia y la de algunos otros cenobios y pueblos del concejo, León, 1945 (ed. facs., León, 1984, p. 72).

${ }^{3}$ Idem. respecto a uno de los cubos que formaban parte de la antigua muralla medieval ${ }^{4}$.

Es posible que esta actual denominación responda a la frecuencia con la que la tradición oral ha relacionado estas cuevas artificiales con los castillos emplazados en sus inmediaciones, como así recogió Aurelio Calvo, cuando refiriéndose "a la parte saliente, entre el rio y la cuesta" de Rueda del Almirante, detallaba que "se aprecian los restos de una cueva, que parece haber sido la entrada al túnel que conducía al Castillo. Ancianos del pueblo con quienes hemos hablado, nos han dicho que la conocieron de niños mucho más abierta y profunda" $\stackrel{5}{-}$.

La importancia del mapa con el que iniciabamos este artículo no sólo radica en la recuperación de una toponimia desconocida, sino que, además, constituye en sí mismo un documento de excepcional valor por tratarse del más antiguo conservado que registra un ejemplo de arquitectura sustractiva medieval en el contexto de la actual provincia de León.

No obstante, el origen del mismo es incierto, pues fue descubierto detrás de un cuadro durante el traslado de parte de los fondos albergados en el antiguo convento de San Marcos de León al edificio Pallarés, actual sede del museo, y ello ha contribuido a generar serias discrepancias y dudas sobre su adsripción cronológica. El estado que el documento presentaba entonces era la-

4 El término «La Casereta» también ha sido utilizado para consignar algunas casas construidas en el Pirineo aragonés, en relación con la formación de antropónimos por derivación. J. A. SAURA RAMí, «Antroponimía benasquesa I. Casas», Archivo de Filología Aragonesa, no 56, 2000, p. 177.

${ }^{5}$ A. Calvo, Op. cit., p. 72. Son numerosas las cuevas que fueron excavadas en los cerros en los que algunos castillos fueron construidos $\mathrm{y}$, en todos los casos, la tradición popular recoge una antigua comunicación entre ellos. 
mentable, por lo que se procedió a su inmediata restauración, la cual determinó su datación en el siglo XVIII debido al tipo de papel utilizado, así como la consideración de éste como uno de los documentos cartográficos más antiguos de la investigación leonesa ${ }^{6}$.

En nuestra opinión, es posible que la cronología a la que pertenece sea aún mucho más temprana, como bien indican las grafías utilizadas. En un somero análisis paleográfico se observa una combinación de humanística cursiva corriente de principios del siglo XVII con algunos restos de la procesal en las letras "C", " $\mathrm{H}^{\prime}$, “ $\mathrm{L}$ ", " $\mathrm{S}$ ” y " $\mathrm{T}$ ", por lo que el documento en cuestión no debería ser fechado más allá de 1600$1630^{7}$. Teniendo en cuenta la data que planteamos para el mismo, es muy posible que no se trate de un dibujo de carácter arqueológico-geográfico, sino de una ilustración en relación con algún pleito, ya que existen numerosos y similares documentos pertenecientes a los siglos XVI-XIX que apoyan esta posibilidad 8 .

${ }^{6}$ L. Grau Lobo, «Eruditos, pioneros e historiadores de la arqueología leonesa», en ArqueoLeón. Historia de León a través de la arqueología, León, 1996, p. 226.

${ }^{7}$ Para llegar a esta conslusión han sido decisivas las aportaciones de Z. García Villada, Paleografía española, Madrid, 1923, pp. 101-104, 321-322 y 329-364; J. Mateu Ibars, Paleografía de la Andalucía occidental, 2 vols., Granada, 1973-1977; T. Marín Martínez et ALII, Paleografía y Diplomática, 2 vols., Madrid, 1977, pp. 323342 (I) y 79-84 (II); A. Millares CARlo y J. M. RuIz ASENCIO, Tratado de Paleografía española, I, Madrid, 1983, pp. 193-202, 221-236, 249-272 y 396-412; ID. Breves consideraciones sobre la documentación castellano leonesa en pergamino en los siglos XIII y XV: Miscelánea de estudios dedicados al profesor A. Marín Ocete, II, Granada, 1974, pp. 739-774 y A. Millares CARLO y J. I. MANTECÓN, Álbum de Paleografía hispanoamericana de los siglos XVI al XVII, México, 1955.

${ }^{8}$ Ma. C. Álvarez Terán, Catálogo XXIX del Archivo General de Simancas. Mapas, planos y dibujos (Años 15031805), Vol. 1, Valladolid-Madrid, 1980.
A tenor de algunos de estos procesos conservados en el Archivo de la Real Chancillería de Valladolid, Fernando Alonso asegura que a aquéllos, "fundamentalmente civiles, que llegaban al Alto Tribunal, se aportaron con frecuencia documentos gráficos como pieza de prueba, siempre por encargo de la Chancillería, bien por iniciativa propia o a petición de una de las partes, constituyendo muchos de ellos auténticos mapas de la zona en conflicto, generalmente por litigios entre términos de concejos o particulares, bien por la propiedad de las tierras o su aprovechamiento, tanto ganadero como agrícola, o incluso por el uso particular o industrial del agua, o sus molinos, en los que quedaban muy detallada toda la geografía, así como las edificaciones existentes" ${ }^{\prime \prime}$.

La posibilidad de que el documento cartográfico de Rueda del Almirante pertenezca a uno de estos procesos viene sustentada por el hecho de contener en un punto determinado del dibujo, concretamente en la zona denominada «El Cueto», un asterisco en el interior de un círculo que además aparece señalado por una flecha. Indicación que solía ser frecuente, entre otras, para señalar con cierta exactitud el lugar del posible litigio.

De ser así, éste que analizamos, a pesar de ser el más temprano, no sería el único relativo a la provincia de León en el que aparece representada una cueva que gozó de ocupación durante el periodo medieval, ya que en el archivo vallisoletano se conserva un óleo datado en el siglo XVIII que fue aportado a un pleito como pieza de prueba en el que se representan algunas localidades de la montaña central leonesa y que, probablemente, debido a su gran tamaño, "fue separado del auto que condi-

${ }^{9}$ F. ALONSO GARCÍA, León en la cartografía histórica, León, 1996, p. 14. 
cionó su aparición, de tal manera que ha llegado a nosotros de forma absolutamente independiente, como manifestación cultural de la sociedad de su época". ${ }^{10}$ Entre los lugares aquí ilustrados se encuentran las localidades de Vega de Gordón, Santa Lucía, San Juan de Villardefrades, Huergas de Gordón, La Pola de Gordón, así como el «Cueto de San Mateo» con la célebre cueva del eremita ${ }^{11}$.

Con todo, de ambos documentos gráficos podemos extraer que, junto a los principales accidentes geográficos como cuetos, cerros, cuestas, ríos, sendas o caminos, la representación de estas cavidades jugaba un papel importante a la hora de completar la información paisajística del entorno, ya que éstas debieron constituir un hito refererencial bien conocido por los vecinos del lugar y con su inclusión se precisaba con mayor exactitud la zona del litigio.

\section{LOS DIBUJOS DEL MAESTRO NACIO- NAL DE RUEDA DEL ALMIRANTE}

Pero no sería hasta 1922 cuando Julián Sanz Martínez hizo pública la existencia de la «Cueva del Cubo» excavada en la localidad de Rueda del Almirante en un exiguo artículo incluido en el número seis

${ }^{10}$ Ibidem, p. 76 y M‥ S. ARRIBAS GonZÁLEZ, Archivo de la Real Chancillería de Valladolid. Selección de planos y dibujos, Valladolid, 1978, lám. 3.

11 “En las proximidades de La Pola también hay huellas de eremitismo: en la falda de «el Cueto de San Mateo» (1.591 m.), hay unas aberturas naturales, en torno a los $1350 \mathrm{~m}$. de altitud; en una de ellas dice la tradición popular que vivió San Mateo, se trata de una gruta cuya entrada ha sido desbastada para darle forma rectangular, está a $2 \mathrm{~m}$. sobre el terreno y mide 140x190 cm.; en el exiguo espacio interno puede verse una roca, de forma regular, a la que se le atribuye función de altar". J. A. GUTIÉRREZ GONZÁLEZ, Poblamiento antiguo y medieval en la montaña central leonesa, León, 1985, pp. 113-114. Véase también, F. J. FERNÁNDEZ CONDE, La religiosidad medieval en España. Alta Edad Media (siglos VII-X), Gijón, 2008, pp. 175-176. de la revista leonesa Renacimiento ${ }^{12}$. Esta noticia fue el resultado de un viaje que el autor realizó el nueve de julio del mismo año a dicho lugar en compañía del abogado del Estado Luís de la Peña y Costa ${ }^{13}$ y del periodista de «El Diario de León» José Sánchez Cañón, al que apodaban «El Lanciense» ${ }^{14}$. Al menos así lo recoge el trece de julio

\section{-}

12 J. SANZ MARTÍNEZ, «La cueva del cubo en Rueda del Almirante», Renacimiento, nº6, 1922, p. 66.

${ }^{13}$ La presencia de este individuo en dicha visita puede resultar un tanto extraña debido a su profesión, sin embargo, a partir del hallazgo de un artículo realizado por Julián Sanz para La Crónica de León en 1922 a propósito de la cueva de la cantera de Alcedo, ésta encuentra sentido: "Me acompañó en esta ligera exploración del interesante yacimiento, mi buen amigo don Luis de la Peña, entusiasta aficionado, que ayudó, no poco, a Julián Sanz Martínez". J. SANZ Martínez, «Cueva de la Cantera en Alcedo», La Crónica de León, p. 2, (17/06/1922). En dicho artículo también se hace alusión a una sesión de la Comisión Provincial de Monumentos de León celebrada el día 11 de junio del mismo año y en la que se acordó "dar cuenta a la Real Academia de la Historia, del descubrimiento efectuado en las cercanías de Acedo, el día 4 del corriente, por don Luis de la Peña y el firmante".

${ }^{14}$ El apodo de José Sánchez Cañón procede de la fascinación e interés que éste tenía hacia el yacimiento lanciense, como así demostraba en la mayor parte de sus artículos publicados en el «Diario de León». Así lo recoge Diego de Moncada en 1922: "rico yacimiento de materiales prehistóricos, protohistóricos e históricos, del que con acierto unas veces, equivocado otras, pero con un gran entusiasmo siempre, se ha ocupado El Lanciense en diversos artículos periodísticos publicados en «El Porvenir de León» y en el «Diario de León». D. DE MONCADA, «El puente del castro», La Crónica de León, p. 1, (05/08/1922). En ellos narraba las excursiones que realizaba y los hallazgos arqueológicos que acaecían en cada una de ellas. Véase, EL LANCIENSE, «Lancia», Diario de León, p. 1, (16/03/1922); ID., «Castros de la edad del bronce», Diario de León, p. 1 (15/04/1922); ID., «Castros de la edad del bronce», Diario de León, p. 1 (19/04/1922) e ID., "Charla arqueológica. Edad de piedra», Diario de León, p. 1 (07/07/1922), entre otros. De esta manera adquirió un importante número de piezas arqueológicas como la colección de monedas que donó en al Museo Arqueológico de León y que luego sus herederos quisieron recuperar: “(...) Informa el Sr. Roa Rico de la situación por que atraviesa, en orden a propiedad de la misma y su posible desaparición del Museo Arqueológico, donde está en depósito, 
del mismo Bernardo Miguel, Maestro Nacional de Rueda del Almirante, en una carta dirigida a Miguel Bravo Guarida, inédita hasta el momento entre los fondos del Archivo Histórico Provincial de León, y que reproducimos completamente por su valor para el presente artículo:

\section{Sr. Don Miguel Bravo:}

León.

Mi distinguido Jefe: El día 9 del actual o sea el domingo último, estuvieron aquí un redactor de "El Diario de León" que se firma "Lasciense", Don Luis de la Peña y Costa, Abogado del Estado y D. Julián Sanz Martínez, Publicista y correspondiente de la Real Academia de la Historia. Les acompañé a ver la Iglesia, cementerio, la cueva grande denominada del Cubo, y al Monasterio de San Miguel de Escalada. De los tres sitios sacaron dibujos aunque muy reducidos, y yo acordándome de V. y por si de algo le valiera, me he apresurado a sacar una cuartilla del cementerio y cuatro de la Cueva del Cubo lo más fielmente que me es dable, advirtiéndole a $V$. que la figura 10 que es la última cruz, no la reprodujeron; yo creo que no la veían bien. De agradecidos que fueron, hoy recibo en certificado un ejemplar de "El arte rupestre en la provincia de León" por Julián Sanz Martínez.

Le adjunto las referidas cinco cuartillas y vea $V$. en qué le puede ser útil éste su S.S. y subordinado.

\section{Bernardo Miguel [Rúbrica]}

Datos a la vuelta

Se llama Cueva del Cubo; está al Sur de Rueda, a unos 80 metros de distancia, y a unos

la Colección de monedas procedentes de Lancia que dejó el Sr. Cañón, «El Lanciense», pues tiene referencias de que sus herederos se proponen rescatar dicha colección y posiblemente venderla. Se cambian impresiones, y se ruega al Sr. Roa haga gestiones oficiosas tendentes a ver la forma de conseguir que dicha Colección no desaparezca e incluso la adquiera esta Comisión". Biblioteca Pública de León (=B.P.L.), Comisión Provincial de Monumentos Históricos y Artísticos de León, Libro de Actas (13/12/1957-27/02/1962), p. 23.
20 metros por bajo de los cimientos de la muralla.

La cueva está orientada al Sur, dando vista al rio Esla.

La forma de la Cueva es semiredonda, con seis concavidades o huecos a su alrededor de la forma de hornos.

Con el transcurso de los siglos y arrastre de tierra, ha ido subiendo el piso de la cueva y se cree que debajo del actual piso hay más del doble del hueco del actual. Vale ${ }^{15}$.

El fatídico hecho de no conservarse las actas de la Comisión Provincial de Monumentos Históricos y Artísticos de la provincia de León correspondientes al año 1922 complica considerablemente la interpretación de la intencionalidad y trascendencia de dicha carta, ya que, por aquellas fechas, tanto Julián Sanz Martínez como Miguel Bravo Guarida eran miembros de ésta ${ }^{16}$. La ausencia de esta información lleva

15 Archivo Histórico Provincial de León (=A.H.P.L.), Fondo Miguel Bravo Guarida, caja 11.603, sig. 139 , s. f.

${ }^{16}$ Debido al gran éxito que recogió el trabajo de investigación de Sanz Martínez sobre El arte rupestre en la provincia de León, así como la importante donación de piezas arqueológicas que realizó a la Comisión de Monumentos de dicha provincia, esta última decidió proponerle como miembro de la misma y correspondiente de la Real Academia de la Historia el 15 de febrero de 1921, y así figura en las actas posteriores a dicha fecha: “(...) Se leyó un oficio de D. Julián Sanz, dando las gracias a la Comisión por el favorable informe que esta emitió sobre su trabajo acerca del arte rupestre en las cuevas de Villasabariego, Villacontilde y Valle, presentado al Certamen Literario celebrado con motivo del pasado Centenario $9^{\circ}$ del Fuero de León, en el que obtuvo a propuesta de esta Comisión el primer premio. La Comisión quedó enterada de dicho oficio. $4^{\circ}$ Leyose después otro del mismo Sr. en que ofrece a la Comisión las colecciones de objetos por él recogidos en Villasabariego, donándolas gratuitamente, si se acepta su oferta. La Comisión acordó aceptarlas: dar al donante las más expresivas gracias por tan generoso donativo de tan interesantes objetos arqueológicos y oficiarle para que se realice la entrega cuando guste, y entonces se reseñará en acta el contenido de dichas colecciones. A propuesta del que suscribe se acordó manifestar a la R. Academia de la 
a cuestionarnos la calidad en la que Sanz Martínez realizó dicha visita, puesto que, de ser como miembro de la Comisión, Miguel Bravo debería estar al corriente de la misma.

Sin embargo, como se desprende del tratamiento que Bernardo Miguel le dispensa a Bravo -mi distinguido jefe-, es muy posible que el maestro estuviese a su servicio informándole de cualquier noticia o acontecimiento relacionado con el patrimonio histórico y artístico de la zona con independencia de este tipo de coincidencias profesionales.

De ello podemos inferir que algunos de los miembros de la Comisión de Monumentos tenían lo que se podría denominar como delegados en determinadas zonas de la provincia leonesa cuya misión era la de

Historia el gusto con que se vería que nombrase correspondiente a D. Julián Sanz como premio a sus notables trabajos de investigación en las citadas cuevas donde ha descubierto grabados y pinturas rupestres de alto interés, y por haber hecho a la Comisión este importante donativo de sus colecciones arqueológicas". B.P.L. Comisión Provincial de Monumentos Históricos y Artísticos de León. Libro de Actas (01/02/1898-24/11/1921), s.f. Igualmente, en la carta objeto del presente estudio Sanz Martínez aparece intitulado como correspondiente de la Real Academia de la Historia. Por su parte, Miguel Bravo Guarida fue nombrado vocal de la Comisión el 7 de junio de 1919 hasta el 26 de febrero de 1950, momento de su fallecimiento: “(...) Acto seguido todos los señores que asistían a la sesión felicitaron muy sincera y cariñosamente al eruditísimo escritor Don Miguel Bravo y Guarida por su merecido nombramiento de Correspondiente de la Real Academia de la Historia; posesionándose este señor del cargo de Vocal de esta Comisión y del de Tesorero de la misma, que estaba vacante por fallecimiento del Sr. Serrano". B.P.L. Comisión Provincial de Monumentos Históricos y Artísticos de León. Libro de Actas (01/02/189824/11/1921). “(...) La presidencia dio cuenta de la defunción del Ilmo. Sr. D. Miguel Bravo Guarida, Vocal de esta Comisión de Monumentos, como Correspondiente de la Academia de la Historia". B.P.L. Comisión Provincial de Monumentos Históricos y Artísticos de León. Libro de Actas (19/07/193117/03/1955), s. f. comunicar al vocal en cuestión las novedades y hallazgos en materia de patrimonio. El caso que analizamos quizá sea uno de los mejores exponentes de este procedimiento, ya que se trata de una carta de carácter personal; sin embargo, en algunas de las actas conservadas de la Comisión se pone en conocimiento de ésta que la información presentada por uno de sus miembros se corresponde con una noticia recibida a través de terceros, e incluso se llega a citar al vecino de la localidad objeto de la misma como muestra de agradecimiento ${ }^{17}$.

Pero no sólo Bernardo Miguel hizo trascender esta visita, ya que uno de los viajeros, José Sánchez Cañón, también la

${ }^{17}$ Como muestra de ello recogemos algunos ejemplos: "El Presidente puso en conocimiento de la Junta que, en unión con los señores Castrillón y Braña, habían ido al cercano pueblo de Navatejera para cerciorarse de la exactitud de una noticia que se les había dado, de haberse descubierto dos pisos de mosaico, al parecer romanos, en el fondo de varios socavones del camino que pasa al pie de dicho pueblo". B.P.L. Comisión Provincial de Monumentos Históricos y Artísticos de León. Libro de Actas (07/1883-05/02/1898), s.f. “A propuesta del Sr. Redondo se acordó nombrar una Comisión que vaya al pueblo de Villalis Ayuntamiento de Villamontán, donde parece ser existían lápidas romanas en la Iglesia y casas de algunos vecinos". B.P.L. Comisión Provincial de Monumentos Históricos y Artísticos de León. Libro de Actas (07/188305/02/1898), s.f. “También expresó que el Domingo 15 del actual fue vendida, según noticias, en pública subasta la colección indicada, habiéndola adquirido el Sr. Teniente fiscal de esta Audiencia provincial". B.P.L. Comisión Provincial de Monumentos Históricos y Artísticos de León. Libro de Actas (07/188305/02/1898), s. f. [f. 130]. "Por el Sr. Álvarez de la Braña se presentó un trozo de Mosaico romano de figuras geométricas que le había donado D. Pascual Vivas vecino de Quintana del Marco partido judicial de La Bañeza, y que encontró en Abril último en una fina de su propiedad al sitio de Los Villares; Que también es partícipe el Sr. Vivas que en el mismo sitio se ha encontrado un sepulcro con huesos y una estatuilla de mármol sin duda de época romana (...). Fue acordado un voto de gracias a este Señor por su donativo". B.P.L. Comisión Provincial de Monumentos Históricos y Artísticos de León. Libro de Actas (01/02/189824/11/1921), s.f. 
hizo pública seis días después para transmitir a sus lectores las impresiones que obtuvo de la misma y mostrar los agradecimientos pertinentes al guía de la excursión:

(...) Reconocidos estamos al maestro nacional de Rueda que nos ha servido de ciceroni enseñándonos el interior de la iglesia y en cuya mesa saboreamos el aromático café y el cigarro ${ }^{18}$.

Volviendo a la misiva dirigida a Miguel Bravo, Bernardo Miguel no sólo actúa como un mero informante de estos hechos, sino que describe con gran exactitud el emplazamiento y morfología de la «Cueva del Cubo» y adjunta la reproducción de unos grabados parietales hallados en su interior, que, de otra parte, también había recogido Sanz Martínez en la mencionada visita para incluirlos en la citada revista Renacimiento.

No obstante, la visión de ambos individuos ante estas manifestaciones murales difiere de forma considerable. En primer lugar, si la calidad de los dibujos realizados por Sanz Martínez es bastante mediocre y los limita a simples trazos que adoptan distintas direcciones de forma esquemática, Bernardo Miguel, en cambio, los reproduce con gran detalle y precisión. En segundo lugar, mientras que el Académico, debido a su patente "obsesión prehistórica" hacia esta tipología arquitectónica ${ }^{19}$, clasificó una vez más estos grabados de antropomorfos

${ }^{18}$ EL LANCIENSE, «Impresiones de un viaje. Cifuentes, Casasola, Rueda, Escalada», Diario de León, p. 1 (15/07/1922).

${ }^{19}$ Véase, V. JIMENO GUERRA, «Los estudios sobre la arquitectura excavada medieval hispana como testimonio sobre la evolución ideológica sobre el medievo», en Perspective contemporane asupra lumii medievale (Perspectives contemporaines sur le monde médiéval), Piteşti (Roumanie), 2009, pp. 236-241. esquematizados del periodo neolítico ${ }^{20}$, el maestro de Rueda los reprensentó de forma objetiva y sin vacilar en cuanto a su carácter cruciforme.

No debe resultar extraña esta disparidad interpretativa, ya que aún sigue apareciendo con frecuencia en la historiografía española debido al acusado esquematismo de estas manifestaciones parietales. Mientras que en algunos casos ciertos motivos cruciformes pueden ser interpretados como figuras antropomorfas, como sostienen Fernández Ibáñez y Lamalfa Díaz ${ }^{21}$, en otros puede suceder a la inversa, como advierte Patrice Cressier ${ }^{22}$. Igualmente, Arnáiz Alonso es consciente de la dificultad que, en ocasiones, existe a la hora de reconocer estos diseños. Para ello, apunta como ejemplo los graffiti practicados en el muro norte de San Miguel de Gormaz (Palencia),

-

${ }^{20}$ J. SANZ MARTÍNEZ, Op. cit., p. 63. Esta adscripción cronológica ya la había realizado con anterioridad para el caso de las cuevas excavadas en las localidades de Villasabariego, Villacontilde y Valle de Mansilla, como publicó en su obra titulada El arte rupestre en la provincia de León. En los tres casos, atribuye erróneamente estos grabados a periodos prehistóricos, argumentado a través de la abundante presencia de objetos de piedra pulimentada, así como fósiles y útiles prehistóricos que fueron encontrados en las inmediaciones de dichas localidades, a pesar de que ninguna de estas piezas fuera hallada en el interior de las mencionadas cavidades. Véase, J. Sanz Martínez, El arte rupestre en la provincia de León, Madrid, 1921.

${ }^{21}$ Como ejemplo señalan el caso de la cueva de «La Calderona» en Palencia. C. FERnÁndeZ IBÁÑEZ y C. LAMALFA DÍAZ, «Manifestaciones rupestres de época histórica en el entorno de la cabecera del Ebro», Munibe, no 57, 2002, pp. 258-259.

22 Esta autora, refiriéndose a los graffiti hallados en el castillo de Escariantes (Almería), señala que "los más interesantes son, sin duda, algunos motivos antropomórficos que, si bien pueden pasar por asociación de una cruz y una letra omega, se prestan, sin embargo, a dudas por la similitud con motivos rupestres prehistóricos". P. CRESSIER, "Graffiti cristianos sobre monumentos musulmanes de la Andalucía Oriental: Una forma de exorcismo popular», en Estudios de arqueología medieval en Almería, Almería, 1992, p. 131. 
donde "se pueden identificar unas representaciones que podría tratarse de figuras humanas, con un diseño en la mayoría de los casos similar a las cruces, por lo que su identificación es complicada. En todos los casos son representaciones con los brazos en posición horizontal y las piernas colocadas en arco" $^{\prime 23}$.

El caso de la «Cueva del Cubo» es, por tanto, una muestra más de esta dualidad interpretativa. Sanz Martínez, como otros muchos investigadores de su época, condicionado por el prehistoricismo reinante derivado de algunos descubrimientos recientes, interpretó estos graffiti de carácter cristiano de la forma que mejor se adecuaba a sus ideas preconcebidas. Donde había una cruz Sanz quiso ver la esquematización de un cuerpo humano ${ }^{24}$. Mientras, Bernardo Miguel estableció claramente un carácter cruciforme para los mismos en un ejercicio de apreciación acertado, puesto que no poseen ni gran simplicidad de líneas ni un acusado esquematismo que pueda conducir a error.

En todo caso, podemos parafrasear a Miguel Ibañez y Teodoro Lejarrága cuando analizando los graffiti del monasterio de San Millán de Suso afirmaban que "lo extraño hubiera sido no encontrar cruces en-

${ }^{23}$ B. ARNAIZ ALONSO, «La expresión espontánea: Graffiti en San Miguel de Gormaz», en San Miguel de Gormaz. Plan integral para la recuperación de un edificio histórico, Valladolid, 2008, p. 202.

${ }^{24}$ Monreal Jimeno recoge cómo en 1923, el Padre Ibero, junto con la ayuda de sus alumnos, recogió la presencia de numerosos grabados cruciformes practicados por los roquedos de la zona de Oña, "que siguiendo las corrientes de su época interpretó como representaciones prehistóricas de figuras humanas, llegando incluso a afirmar que la presencia de estos signos testimonia la existencia de enterramientos". A ello añade cómo ha sido imposible "comprobar sobre el terreno varios de los grabados citados, sin la necesaria precisión, por Ibero, pero resulta evidente que la mayor parte de ellos son cristianos y altomedievales". L. A. MONREAL JIMENO, Eremitorios rupestres altomedievales. El alto valle del Ebro, Bilbao, 1989, p. 77. tre ellos"25. Y es que la imagen de la cruz en todas sus variantes es uno de los temas más repetidos en los grabados de carácter cristiano desde la época medieval hasta el siglo $\mathrm{XX}$ tanto en arquitecturas construidas como excavadas ${ }^{26}$, hecho que también dificulta su concrección cronológica.

Las figuras que Bernardo Miguel recogía en cuatro cuartillas son seis cruces perfectamente definidas, dos elementos de morfología oblonga identificados con los brazos de otros dos posibles cruciformes, un tercero de carácter arborescente que podría responder al caso anterior $\mathrm{y}$, por último, una figura de aspecto geométrico que formaría parte de un elemento ya desaparecido. Todos ellos fueron reproducidos

${ }^{25}$ M. IbÁÑEZ RODRÍGUEZ y T. LEJARRAGA NiETO, Los grafitos del monasterio de San Millán de Suso, La Rioja, 1998, p. 23.

${ }^{26}$ Fabiola Gómez y José Ignacio Royo apuntan con respecto a los graffiti murales aragoneses que "dentro de los motivos de carácter religioso, la figura que aparece con mayor profusión son los cruciformes en sus múltiples variantes: desde los motivos más simples de cruces griegas o latinas, con y sin peana y con extremos simples o compuestos, hasta las cruces compuestas, como las patriarcales, las de Caravaca, los calvarios, las cruces con sudario, así como sus derivaciones. Este tipo de representaciones suele aparecer tanto en edificios civiles como religiosos, aunque se concentran en estos últimos". Asimismo, añaden que los motivos cruciformes se encuentran presentes "tanto en grabados al aire libre, como en edificios históricos, desde la Alta Edad Media, hasta bien entrado el siglo XIX e incluso comienzos del siglo XX". J. I. ROYO GUILLÉN y F. GÓMEZ LECUMBERRI, «Panorama general de los graffiti murales y de los grabados al aire libre medievales y postmedievales en Aragón: Paralelos y divergencias», Āl-Qannī̌s, 2002, pp. 64 y 146. Por su parte, Carmelo Fernández y Carlos Lamalfa indican para el entorno de la cabecera del Ebro que "la cruz, como no podía ser de otra manera, es el signo/símbolo más abundante en la zona geográfica motivo de nuestro estudio, todas ellas grabadas, realizándose en diferentes lugares y con diferentes cometidos". Y añaden que "de especial consideración han resultado determinados lugares que tienen en común el tratarse de abrigos rupestres, cuya acumulación de símbolos a través de generaciones ha sido reiterada y donde la cruz sigue siendo el motivo principal". C. FERNÁNDEZ IBÁÑEZ y C. LAMALFA DÍAZ, Op. cit., p. 258. 
manteniendo su tamaño natural a excepción de la figura identificada con el número 8 , la cual se corresponde con la mitad de sus dimensiones reales (Figuras 2, 3, 4 y 5).

La mayor parte responden al modelo de cruz de brazos patados e incluso algunos de ellos, como es el caso de la figura número 2, se encuentran rellenados por un entramado de líneas incisas de carácter horizontal, vertical y oblicuo, muy habitual en los graffiti practicados en cavidades artificiales datadas en el periodo altomedieval. Así se observa en cuevas como las de Gurtupiarana, excavadas en la localidad alavesa de Urarte, donde abundan "las formas reticulares de muy fina trama, muchas de las cuales se presentan aisladas, como si tuviesen valor en sí mismas, aunque no resulten figuras comprensibles o de algún modo identificables. El número de líneas resulta abrumador, predominando las rectas paralelas cruzadas por otras transversales con las que constituyen campos reticulares, frecuentemente de amplias dimensiones. Incluso cuando aparece una figura reconocible, acostumbra a estar macizada por este tipo de retículas" 27 . Pero esta práctica no es exclusivamente hispana, ya que es visible en lugares como la península de Anatolia en algunas de las pinturas murales de las cavidades excavadas en la Capado$\mathrm{cia}^{28}$, por lo que puede considerarse como un motivo universal, extensivo, incluso, a la arquitectura construida. En este sentido, y a escasos cinco kilómetros de la «Cueva del Cubo», hemos hallado graffiti de similares

${ }^{27}$ L. A. MONREAL Jimeno, Op. cit., p. 111.

${ }^{28}$ Aparece como elemento de relleno en los pantalones del soldado protagonista de «La matanza de los inocentes», así como en los de San José en «La entrada en Jerusalén» de Bahattin Samanliği Kilisesi. Igualmente, es utilizado como un motivo decorativo, a modo de celosía, en las trompas de la cúpula de Ağaç altI kilise, entre otras. N. THIERRY, Nouvelles églises rupestres de Cappadoce: régio du Hasan Dagi. (New rockcut of Cappadocia), Paris, 1963, pp. 159 y 165. características, e inéditos hasta este momento, en las enjutas del segundo arco formero más próximo al presbiterio por el lado norte en la iglesia altomedieval de San Miguel de Escalada. Así, en la más oriental, y junto a unos motivos epigráficos en los que puede leerse: "MONIONI MONACHO" y "FRUCTO:SO MONACHO", fueron representadas cuatro letras " $\mathrm{D}$ ", alguna de las cuales parece formar parte de otro posible conjunto epigráfico, y dos estructuras de carácter longitudinal macizadas con las líneas ya referidas ${ }^{29}$ (Figura 6). Asimismo, en la enjuta adyacente encontramos representado el último motivo citado, también en número de dos, aunque precedido en este caso de la letra " $\mathrm{M}$ ", sobre otro grupo de grafías entre las que podemos leer en dos ocasiones el nombre del santo titular del templo, "MICAEL" 30 , además de repetirse uno de los anteriores, "MONIONI MONACHO" (Figura 7).

De aquellos grabados parietales recogidos por Bernardo Miguel hace ochenta $\mathrm{y}$ tres años, hoy es imposible identificar alguno debido al estado absolutamente ruinoso que presenta la «Cueva del Cubo» de Rueda del Almirante, además de entrañar un serio peligro para la integridad física de quien se aventure a adentrarse en su interior. No obstante, en el muro noroeste de esta cavidad, y cercano a la cubierta de la misma, todavía es posible identificar de forma relativamente factible un graffito de

${ }^{29}$ Estas estructuras también las hemos podido observar en el exterior del edificio, concretamente en el intradós del vano de entrada al mismo. No obstante, el estado de conservación que éstas presentan es lamentable debido a la erosión y vandalismo que han sufrido a lo largo de la historia.

${ }^{30}$ Hemos de advertir cómo la "I" de uno de ellos parece adoptar la misma morfología que los reticulados practicados en un nivel superior, aunque sin llegar a rellenarse su interior. Es por ello que los superiores podrían tratarse de una "I" macizada y haber sido realizados para formar parte de una palabra, posiblemente una vez más Micael, ya que se encuentran precedidos por la letra " $\mathrm{M}$ ". 
morfología cruciforme insertado en una circunferencia de once centímetros de diámetro (Figura 8). Debido al evidente carácter cristiano que poseía este espacio, como queda demostrado a través de los dibujos realizados, es posible que esta representación se trate de un crismón de gran simplicidad que respondería a dos posibles opciones. La primera de ellas sería la combinación de las letras griegas I (iota) y X (ji) (Iesus Xristos) enmarcadas en un círculo, mientras que en la segunda se sustituiría la letra $I$ (iota) por la letra $P(r h o)$. Empero, es posible que esta última opción sea simplemente el resultado de la rugosidad que presenta la superficie sobre la que este graffito fue practicado, ya que la hipotética letra $P(r h o)$ no posee ninguna incisión lo suficientemente marcada como para confirmar dicha hipótesis.

No debemos extrañarnos de la presencia de estos anagramas en los muros de estos espacios excavados altomedievales, por ser un hecho frecuente que encontramos, entre otros, en algunos sectores marginales de las iglesias excavadas de las Gobas de Laño (Treviño), donde se han hallado "algunas figuras simbólicas, como el crismón, en su variante de cruz monogramática, con el «alfa» y el «omega», defectuosamente trazadas; una cruz de brazos iguales enmarcada en un círculo, que, entre otros paralelos, recuerda la análoga que ocupa la jamba del arco triunfal de la iglesia de S. Esteban de Viguera, relacionada con las cuevas, y también la no lejana, aunque más confusa, de la jamba de una de las cuevecillas de «Krucia» (Faido)"31.

\section{HACIA LA INMINENTE DESAPARICIÓN DE LA «CUEVA DEL CUBO»}

El estado que la cavidad de Rueda del Almirante presenta en la actualidad es,

${ }^{31}$ L. A. MONREAL JiMENO, Op. cit., pp. 123-124. como ya hemos adelantado, lamentable, ya que se encuentra colmatada en casi su totalidad, como ya venía ocurriendo cuando el maestro de Rueda del Almirante informaba a Miguel Bravo Guarida. La meteorización de la cubierta y los muros que la conforman, la introducción de arcilla procedente del exterior a causa de la escorrentía, así como de los recientes desprendimientos que ha sufrido, han dado lugar al avanzado estado de deterioro al que ha llegado hoy. Por tanto, estos hechos plantean una serie de dificultades que complican considerablemente su estudio, como es la lectura de su morfología primigenia $\mathrm{y}$, por ende, la realización de un correcto levantamiento planimétrico $^{32}$ (Figura 9).

Aun así puede serguirse observando, como ya describía Bernardo Miguel, un espacio pseudo-semicircular, en cuyos muros fueron practicadas una serie de concavidades, en número de seis y de forma relativamente simétrica ${ }^{33}$. Así, en torno a la "exedra" central se practicaron otras contiguas en cada uno de sus lados.

Debido a las certezas materiales conservadas en la actualidad es muy posible que este espacio poseyese en su origen una

\footnotetext{
${ }^{32}$ Desconocemos la profundidad de los sedimentos que ocultan el pavimento originario, información que tan sólo una intervención arqueológica podría proporcionar. Sin embargo, presuponemos que la pérdida en altura se encontraría alrededor de un metro.

${ }^{33}$ La profundidad que éstas presentan es variable debido a que la erosión que este espacio ha sufrido ha sido desigual. Así, las concavidades ubicadas en el centro y extremo izquierdo presentan una mayor profundidad y definición con respecto a las restantes, mientras que la practicada en el extremo derecho posee una mayor erosión debido a su actual desprotección. No obstante, es necesario señalar que lo que advertimos en la actualidad tan sólo son las partes superiores que conformaban estas exedras, por lo que su parte inferior pudo poseer una mayor profundidad. Sin embargo, de su actual morfología se deduce que podrían ser pseudo-semicirculares.
} 
planta centralizada, repitiéndose a lo largo de todo su perímetro este sistema de articulación mural (Figura 10). De esta manera, en una búsqueda de paralelos formales que pudiesen ayudarnos a plantear una posible hipótesis sobre su funcionalidad, no hemos encontrado ninguna analogía dentro del ámbito de los conjuntos excavados peninsulares. El único espacio que parece presentar algunas similitudes con el excavado en Rueda del Almirante es una de las cuevas artificiales emplazadas en la localidad de Bobadilla (La Rioja). La riojana posee un espacio centralizado, con paredes ligeramente cóncavas, a partir del cual se accede a "tres pequeñas cámaras de planta ultrasemicircular que presentan sistemas de cierre individuales" ${ }^{\prime 34}$. Sin embargo, sí existen ejemplos similares en obras de fábrica foráneas de época tardorromana. Así, esta articulación interior del espacio se encuentra presente en algunas construcciones de carácter funerario erigidas fuera de nuestras fronteras durante el Bajo Imperio. Ejemplo de ello es la Iglesia de Santa Constanza (Roma), el Mausoleo de Santa Helena (Roma) o el Mausoleo de Diocleciano del complejo palatino de Spalato (Croacia) ${ }^{35}$. No obstante, la ausencia de esta morfología en la arquitectura de fábrica española aleja

\footnotetext{
${ }^{34}$ Ibidem, pp. 179 y 405.

${ }^{35}$ En el caso de estos tres mausoleos, esta articulación interior de los muros no viene dada solamente por la presencia de exedras semicirculares practicadas a intervalos regulares, sino por la combinación de éstas con aquellas de planta cuadrangular. Igualmente, y con respecto a estos tres, la planimetría de la cueva de Rueda del Almirante quedaría reducida a la mitad. Ma. A. UtRERO AGUDO, Iglesias tardoantiguas y altomedievales en la Península Ibérica. Análisis arqueológico y sistemas de abovedamiento, Madrid, 2006, pp. 210 y 398 y J. M. Noguera Celdrán, El Casón de Jumilla (Murcia): estudio arqueológico e interpretación de un mausoleo tardorromano, Alicante (ed. digital de la Biblioteca virtual de Miguel de Cervantes), 2007, p. 265.
}

la posible influencia, al menos directa, de estos espacios ${ }^{36}$.

Con todo, la cavidad excavada en Rueda del Almirante es poseedora de una gran singularidad planimétrica dentro del territorio hispano peninsular $\mathrm{y}$, por ende, debe ser considerada como un espacio de gran valor arquitectónico, no sólo para el conocimiento del fenómeno sustractivo altomedieval, sino también para la valoración de la importancia del mismo.

La trascendencia de la que este espacio gozó durante la década de los años veinte por parte de aquellos interesados en descubrir y dar a conocer la existencia de los bienes patrimoniales que, hasta entonces, eran ignorados o poco estimados, pronto fue en detrimento provocando la fatalidad de su irremediable y vertiginosa desaparición. Una actuación arqueológica sería de notable trascendencia en la recuperación de esta cavidad excavada que pronto tan sólo será recordada a través de la toponimia.

\footnotetext{
${ }^{36}$ Bien es cierto que dentro del territorio hispano existe algún ejemplo de planta centralizada que presenta algunas similitudes con estos últimos como es el caso del Mausoleo de Centcelles (Tarragona). J. ARCE, Centcelles, el monumento tardorromano, Roma, 2002 y Ma. A. UtRero AgUdo, Op. cit., pp. 543-544.
} 


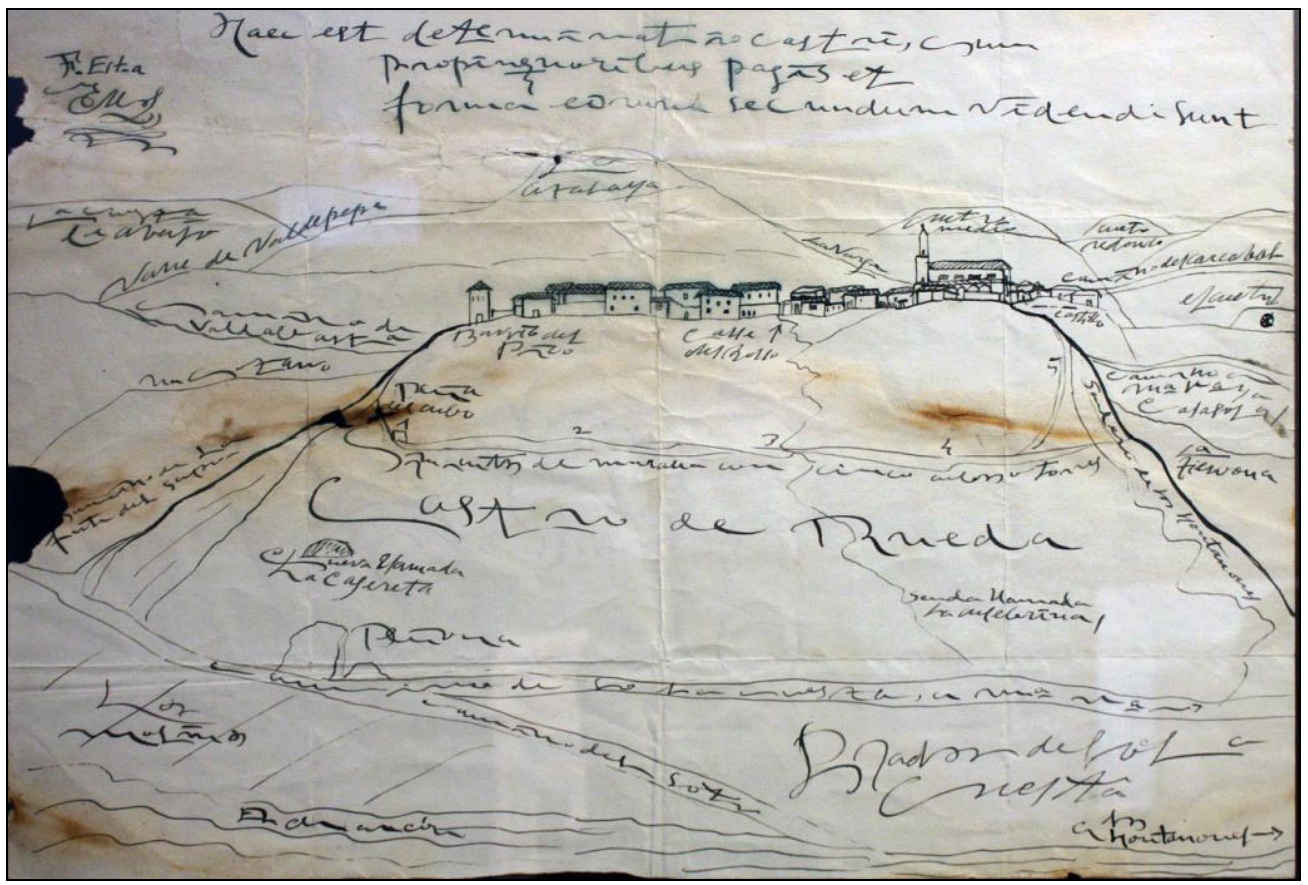

- Fig. 1. Mapa de la localidad de Rueda del Almirante, ca. 1600-1630. Museo Provincial de León (n⿳⺈ de inv. 1995/9/1).

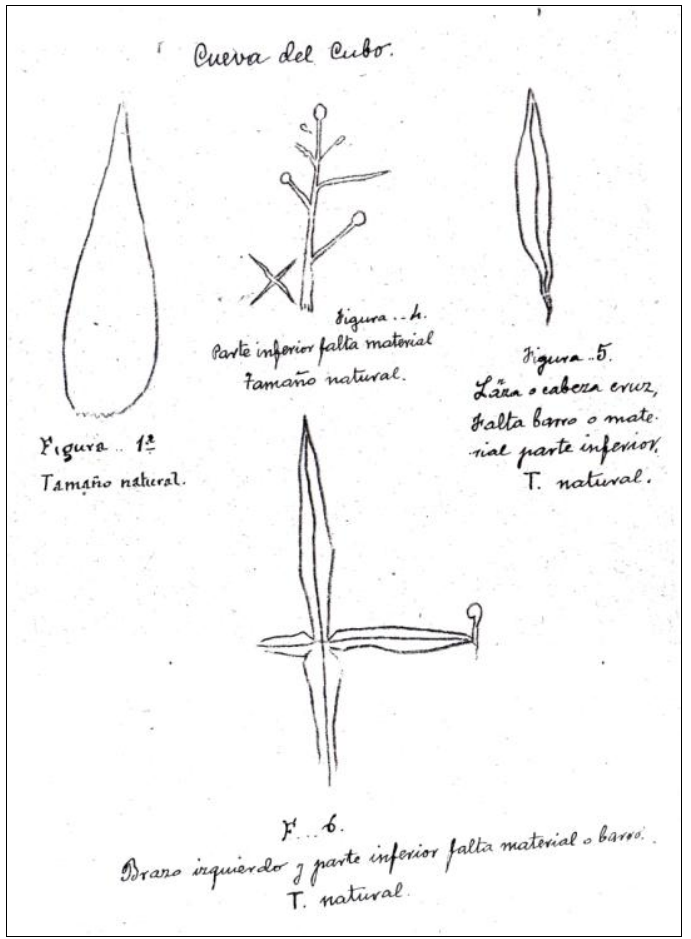

- Fig. 2. Dibujos realizados por el Maestro Nacional de Rueda del Almirante en 1922. Archivo Histórico Provincial de León, Fondo Miguel Bravo Guarida.

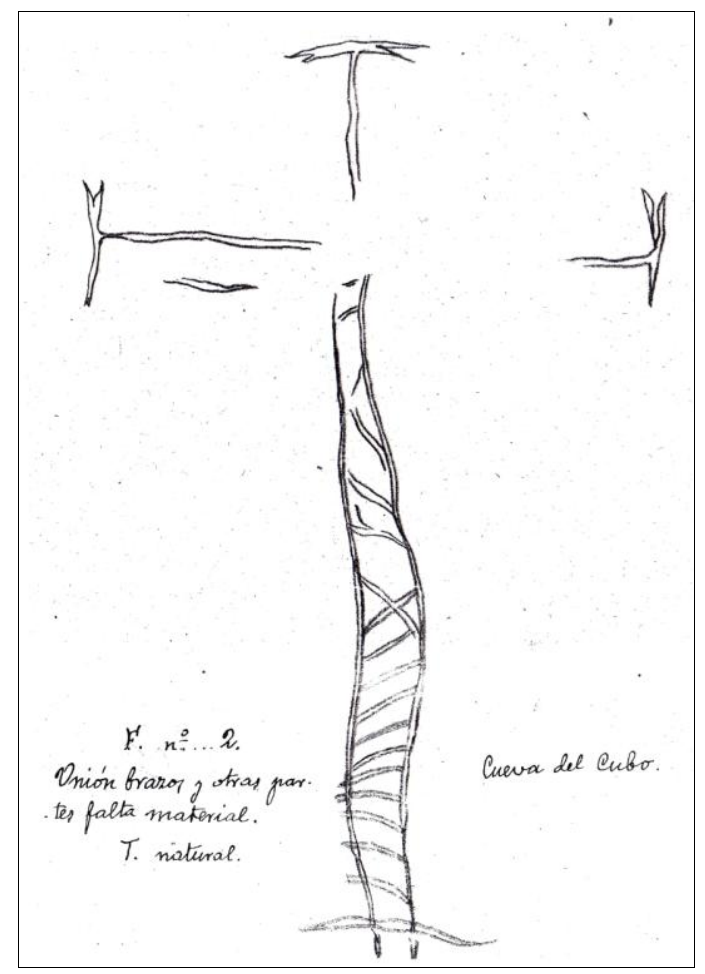

- Fig. 3. Dibujos realizados por el Maestro Nacional de Rueda del Almirante en 1922. Archivo Histórico Provincial de León, Fondo Miguel Bravo Guarida. 


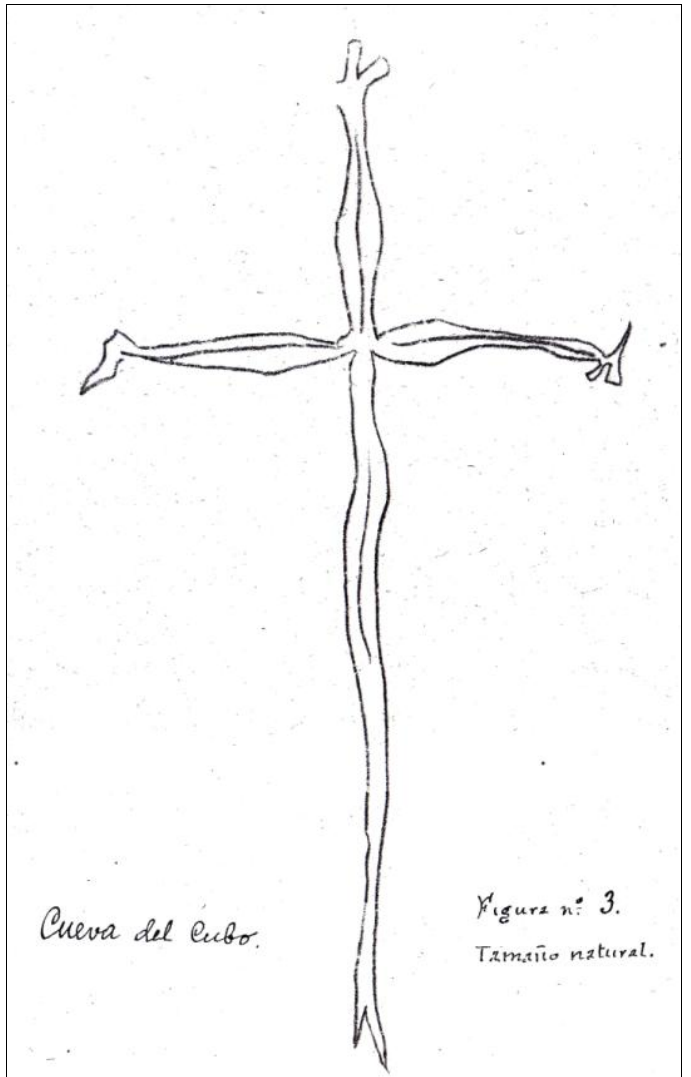

- Fig. 4. Dibujos realizados por el Maestro Nacional de Rueda del Almirante en 1922. Archivo Histórico Provincial de León, Fondo Miguel Bravo Guarida.
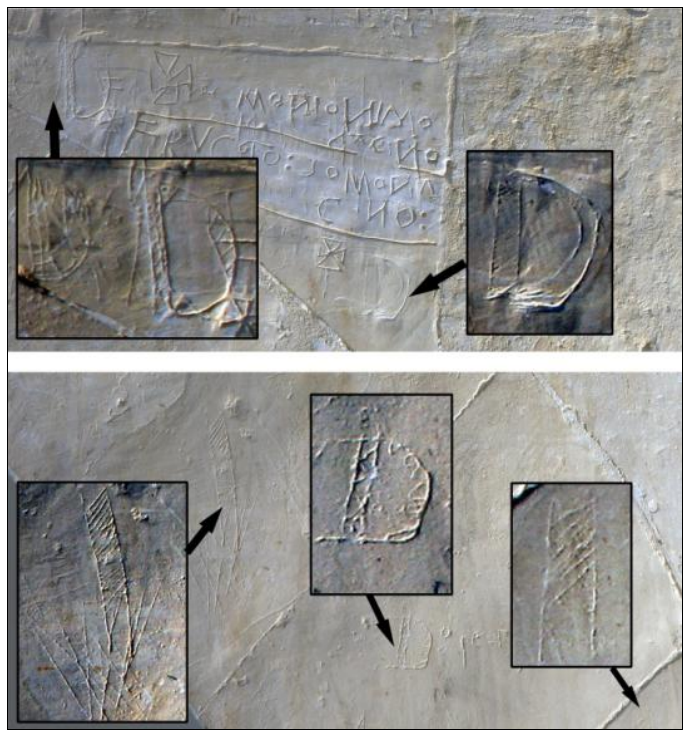

- Fig. 6. Graffiti en la enjuta oriental del arco. Iglesia de San Miguel de Escalada. (Foto: Autora).

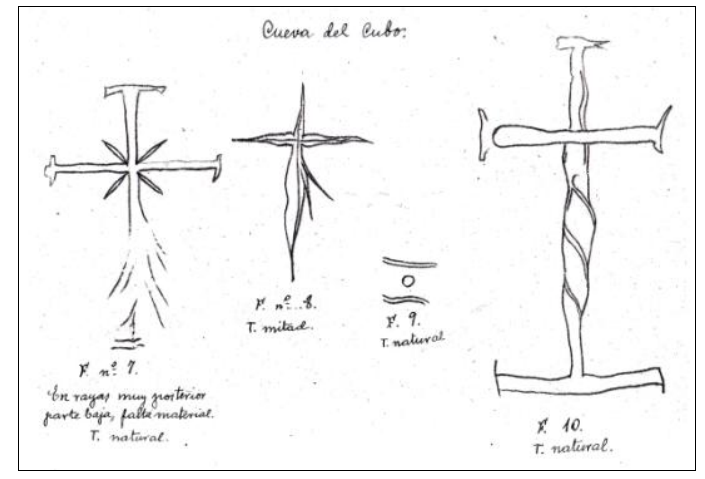

- Fig. 5. Dibujos realizados por el Maestro Nacional de Rueda del Almirante en 1922. Archivo Histórico Provincial de León, Fondo Miguel Bravo Guarida.

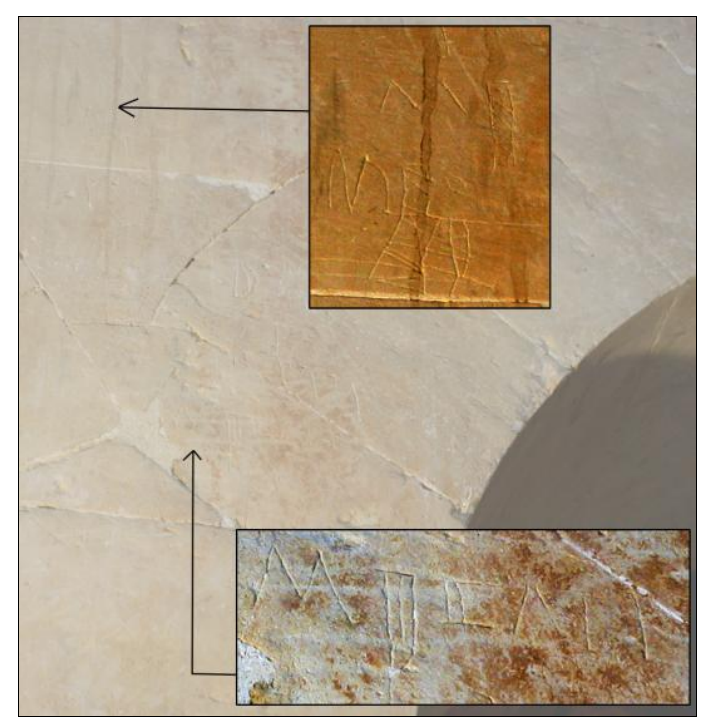

- Fig. 7. Graffiti en la enjuta occidental del arco. Iglesia de San Miguel de Escalada. (Foto: Autora). 


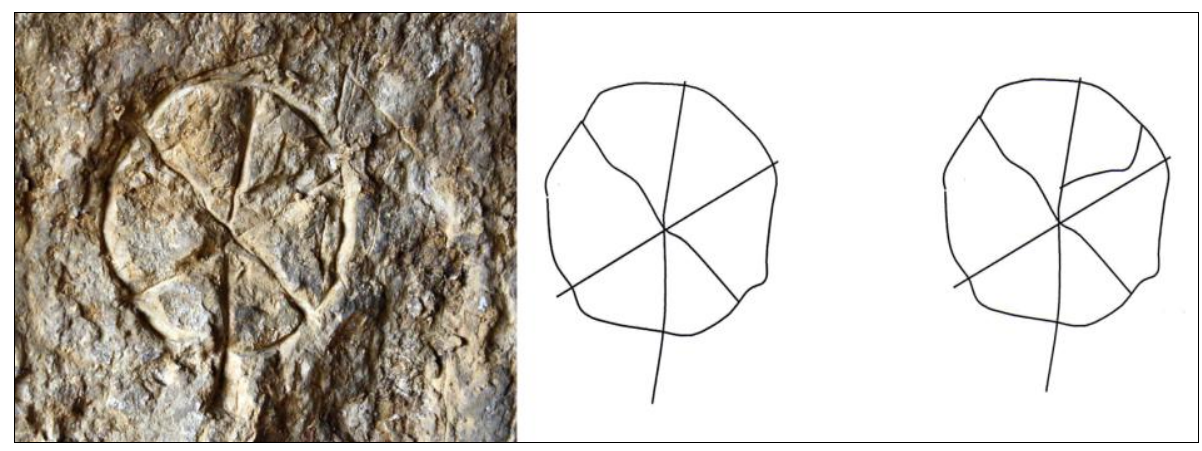

- Fig. 8. Graffito hallado en la «Cueva del Cubo» e interpretaciones dibujadas del mismo. (Foto y dibujos: autora).

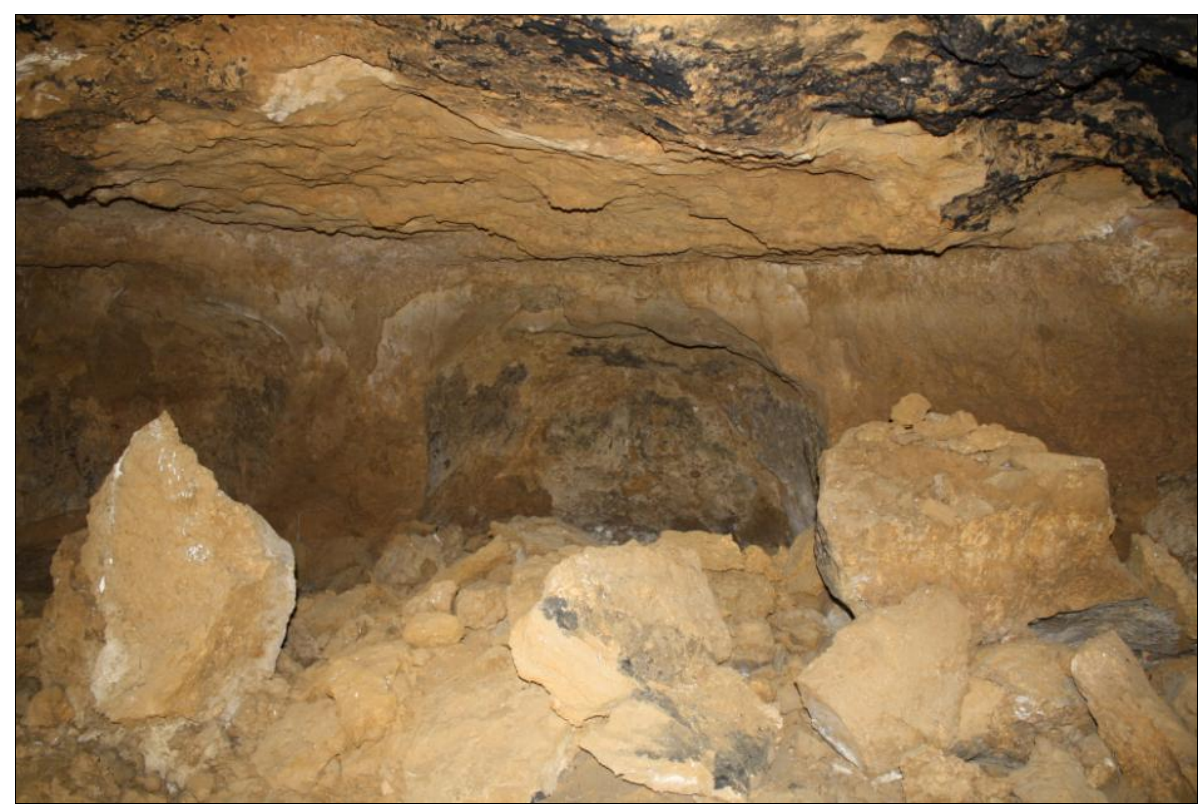

- Fig. 9. Interior y estado actual de la «Cueva del Cubo» de Rueda del Almirante. (Foto: Autora).

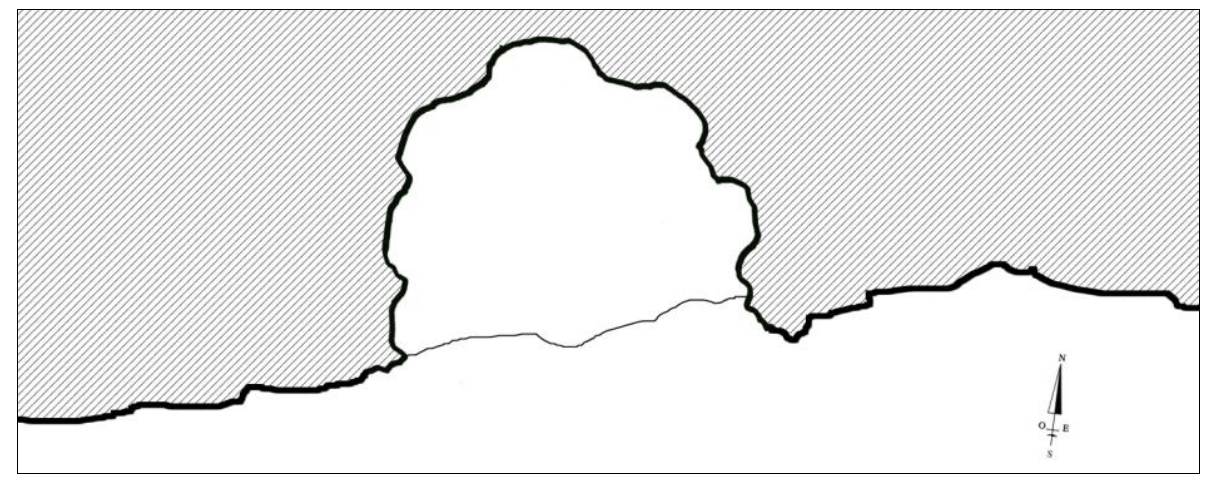

- Fig. 10. Dibujo aproximativo de la planta de la «Cueva del Cubo» de Rueda del Almirante. (Dibujo: Autora). 